\title{
Reciprocal cooperation - Norway rats (Rattus norvegicus) as an example
}

\author{
Manon K. Schweinfurth \\ University of St Andrews, School of Psychology \& Neuroscience, Origins of Mind, St Mary's Quad, St Andrews, KY16 9JP \\ Correspondence: ms397@st-andrews.ac.uk / +44 (0)1334 463460
}

Many animals cooperate even with unrelated individuals in various contexts, like providing food or allogrooming others. One possibility to explain the evolution of such apparently altruistic behaviour is reciprocity. In reciprocal cooperative interactions, individuals help those partners that have been previously cooperative and therefore exchange favours. This conditional help follows rules like "I help you because you helped me". These rules are often assumed to be so cognitively demanding that they may be limited to humans. In this chapter, I will shed light on the cognitive underpinnings of reciprocal cooperation by reviewing work on one of the yet best-studied animal in this research area, the Norway rat (Rattus norvegicus). Various studies have demonstrated that Norway rats reciprocally exchange different goods and services. They most likely form attitudes towards social partners that are based on the cooperation level of the last encounter, which they remember over long time spans. Cooperation decisions based on attitudes appear cognitively less complex than calculations of received and given favours. Thus, reciprocal cooperation based on this cognitive mechanism might be in fact more widespread among non-human animals than commonly believed.

Keywords: Norway rats, cooperation, reciprocity, exchange, help 


\section{Reciprocity - ultimate and proximate evolutionary mechanisms}

Many animals live, at least during some stage of their lives, in groups, ranging from loose and open aggregations to highly complex and closed societies (e.g. Krause \& Ruxton, 2002). Interactions within such groups are often characterised by competition and cooperation. The evolution of competitiveness is straightforward as it leads to direct benefits to the actor. However, why individuals provide benefits to others is more difficult to explain (Darwin, 1859). The most prominent explanation is kin selection, where individuals direct their help to related partners, thereby gaining indirect benefits through closely related individuals producing offspring that share genes with the helper (Hamilton, 1964). Nevertheless, cooperation frequently takes place also between unrelated individuals where kin selection cannot explain the evolution of helpful behaviours (Dugatkin, 1997).

One possible explanation for help between non-relatives is the reciprocal exchange of help, in which individuals take turns in providing goods or services to each other (Trivers, 1971). By exchanging received with given favours, the partners both receive benefits at some stage. Thus, the overall net benefit is greater compared to situations in which individuals never help and hence never receive any help. However, such reciprocal cooperation is prone to cheating, where one partner stops the interaction after receiving help. Thus, to ensure that help is only directed to cooperative partners, which will pay back favours later on, strategies that are dependent on the partner's behaviour need to evolve (Axelrod \& Hamilton, 1981). Different decision rules of reciprocal helping have been discussed (reviewed in: Schweinfurth \& Call, 2019a, Figure Schweinfurth.1): During direct reciprocity, individuals follow the rule "I help you because you helped me" (Trivers, 1971), while during indirect reciprocity, individuals help others following the rule "I help you because you were helpful to somebody before" (Alexander, 1987). Finally, in generalised reciprocity the generous rule "I help you because I was helped by someone" is applied (Boyd \& Richerson, 1989).

Reciprocal cooperation is ubiquitous in the daily life of humans, with evidence found in both correlational and experimental studies (reviewed in: Bowles \& Gintis, 2011). However, whether reciprocal 
cooperation is also common in other animals is hotly debated. Some authors argue that reciprocity is rare in non-human animals (Clutton-Brock, 2009; Hammerstein, 2003), mainly because it appears too cognitively challenging (Clements \& Stephens, 1995; Ramseyer, Pelé, Dufour, Chauvin, \& Thierry, 2006; Stevens, Cushman, \& Hauser, 2005; Stevens \& Gilby, 2004). To the contrary, others show evidence for reciprocal help in a wide range of species (e.g., Schweinfurth \& Call, 2019; Taborsky et al., 2016) and argue that reciprocity is not necessarily cognitively demanding (Brosnan \& de Waal, 2002; Carter, 2014; Schino \& Aureli, 2009, 2010; Schweinfurth \& Call, 2019a). In this chapter, I aim at summarising knowledge on specific cognitive challenges associated with reciprocity and explore the different cognitive underpinnings of reciprocity. I do so by employing the best-studied non-primate animal model, the Norway rat (Rattus norvegicus). First, I summarise why rats are a good model organism for reciprocal cooperation and how reciprocity is usually tested in Norway rats, followed by a synopsis of the evidence of reciprocity in Norway rats. Thereafter, I discuss which information Norway rats use in order to reciprocate help and which different commodities they use to help others. Finally, I review how rats memorise the behaviour of their partner in order to help only cooperative conspecifics and which cognitive mechanisms rats are likely to use.

\section{Norway rats as model organism}

Norway rats are a great candidate for studying reciprocal cooperation because of (i) their highly gregarious life, which fulfils all criteria for the evolution of reciprocity (cf. Trivers, 1971) and (ii) their great trainability, which enables experimental studies under controlled conditions (cf. Munn, 1950).

Norway rats are highly gregarious animals, living in colonies of up to 200 individuals with which they repeatedly interact (Telle, 1966). Colonies consist of animals of both sexes (MacDonald et al., 1999) and different levels of relatedness (Puckett et al., 2016). Rats individually recognise each other by odour (Gheusi, Goodall, \& Dantzer, 1997; Hopp, Owren, \& Marion, 1985). They show a range of affiliative behaviours under natural conditions, such as allogrooming, huddling and food sharing (Barnett 
\& Spencer, 1951). In fact, when isolated, rats show depression-like behaviours (Brenes \& Fornaguera, 2008; Hurst et al., 1997), emphasizing the importance of social partners.

Rats are characterised by their good learning ability and suitability for lab studies, which is why they have become one of the main model organisms in biological, psychological and medical research. Testing rats in the lab allows for a careful dissection of the proximate mechanisms of their gregarious life style. In various experimental studies, rats have demonstrated their high propensity to cooperate (reviewed in: Wrighten \& Hall, 2016). Rats prefer to cooperate, even if there exists the possibility to achieve the same reward individually (Schuster \& Perelberg, 2004). Further, if they have a choice between a reward for themselves or for themselves and a partner, they opt for the latter mutually rewarding option (Hernandez-Lallement, van Wingerden, Marx, Srejic, \& Kalenscher, 2015). Rats cooperate in several contexts. They have been repeatedly shown to help conspecifics by, for instance, freeing trapped partners (e.g. Bartal et al., 2016; Ben-Ami Bartal, Decety, \& Mason, 2011; Ben-Ami Bartal, Rodgers, Bernardez Sarria, Decety, \& Mason, 2014; Sato, Tan, Tate, \& Okada, 2015; Schwartz, Silberberg, Casey, Kearns, \& Slotnick, 2016; Silberberg et al., 2013). Furthermore, they groom conspecifics (e.g. Barnett, 1963; Schweinfurth, Stieger, \& Taborsky, 2017; Yee, Cavigelli, Delgado, \& McClintock, 2008). Finally, they help conspecifics by donating food to each other (e.g. Colin \& Desor, 1986; Grasmuck \& Desor, 2002; Krafft, Colin, \& Peignot, 1994; Littman, Lanski, \& Rhine, 1954; Łopuch \& Popik, 2011; Márquez, Rennie, Costa, \& Moita, 2015; Munn, 1950; Rutte \& Taborsky, 2007).

\section{The food exchange paradigm}

Evidence for reciprocal cooperation from many species often stems from correlational field and captive studies (reviewed in: Taborsky et al., 2016). While such findings are highly interesting as they demonstrate the occurrence of a behaviour under relevant natural conditions, they are usually not sufficient to test the proximate basis of such behaviour. For example, correlations of given and re- 
ceived help may be explained by confounding factors such as spatial proximity, social bonds or hierarchical position. Although some of these observational studies statistically control for those factors, they do not allow causal conclusions (e.g. Silk, 2007). Experimental evidence based on the manipulation of behaviours is therefore indispensable to disentangle reciprocal rules from other possibly confounding factors.

To investigate whether rats help each other reciprocally, almost all published experimental studies have employed variants of a two-player sequential food exchange task (Figure Schweinfurth.2). This is a well-established method that has been used in a range of species (e.g. azure-winged magpies: Horn, Scheer, Bugnyar, \& Massen, 2016; capuchin monkeys: de Waal \& Berger, 2000; dogs: QuervelChaumette, Dale, Marshall-Pescini, \& Range, 2015; humans: House, Henrich, Sarnecka, \& Silk, 2013; jackdaws: Schwab, Swoboda, Kotrschal, \& Bugnyar, 2012; macaques: Massen, van den Berg, Spruijt, \& Sterck, 2010; non-human great apes: Amici et al., 2014; tamarins: Cronin, Schroeder, \& Snowdon, 2010). In addition, this method has been employed in a multi-player settings (e.g. capuchins, macaques and marmosets: Burkart \& van Schaik, 2013; chimpanzees: Suchak et al., 2016). In general, this task consists of one individual, i.e. the social partner, that donates food to a second individual, i.e. the focal individual. Thereafter the roles are reversed and the donation rate of the focal individual towards its partner is observed. This task allows researchers to test whether the focal individual's donation rate is conditional on the partner's behaviour. For this, the donation rates of focal individuals are compared with a cooperating partner, which had provided food, and a defecting partner, which had not provided any food. If rats donate food to each other according to reciprocal decision rules, focal rats are expected to donate food more often to cooperating than to defecting partners.

\section{Reciprocal food donations in Norway rats}


There is compelling evidence for reciprocal cooperation in Norway rats (summarised in Table Schweinfurth.1). Domesticated and undomesticated Norway rats have been shown to reciprocate food donations by providing more food to partners that previously helped them compared to partners who refused to help (lab rats: Li \& Wood, 2017; Simones, 2007; Viana, Gordo, Sucena, \& Moita, 2010: wildderived rats: Rutte \& Taborsky, 2008; Schneeberger, Dietz, \& Taborsky, 2012; Schweinfurth \& Taborsky, 2016). In addition to this direct reciprocal decision rule, female wild-derived rats apply the rules of generalised reciprocity when helping strangers (Rutte \& Taborsky, 2007). Interestingly, males do not follow such rather generous rules (Schweinfurth, Aeschbacher, Santi, \& Taborsky, 2019). Reciprocal food exchanges have been demonstrated between both related and unrelated partners (Schweinfurth \& Taborsky, 2018c). All these studies, conducted in various labs and using different methods, suggest that reciprocal cooperation in rats is a robust finding. Still, one has to make sure that the results cannot be explained by alternative mechanisms (cf. Dolivo, Rutte, \& Taborsky, 2016; Zentall, 2015).

First, rats that received food by cooperators but not by defectors might show a general increase in activity, which translates into increased food provisioning levels towards cooperative partners. However, experiments in which focal rats received the same amount of food, either provided by the cooperating partner rat or by the experimenter after the defecting partner rat had not provided any food, revealed the same reciprocal responses (Rutte \& Taborsky, 2007, 2008; Schneeberger et al., 2012). In addition, if focal rats received food by a remotely controlled food dispenser in the mere presence of a partner, focal individuals did not increase their food donations for this seemingly cooperative partner (Schmid, Schneeberger, \& Taborsky, 2017). This shows that biased food intake by cooperators cannot explain reciprocity in rats.

Second, the action of food provisioning might be a conditioned response, triggered by receiving food, and might thus be independent of its social function. If this would be the case, one would expect that rats, which received help, would show donations also outside a social context. However, rats provided 
more food to their partners than to empty cages after experiencing cooperating partners (Rutte \& Taborsky, 2007, 2008; Schweinfurth et al., 2019; Schweinfurth \& Taborsky, 2016). This indicates that rats take into account whether a partner rat receives their food donations and adjust their behaviour accordingly.

Third, rats may copy their partner's behaviour without realising cooperation levels when returning a received favour. If this would be true, rats shall not be able of transferring between different food provisioning tasks that make copying impossible. To test this alternative, rats experienced partners in one task, i.e. pulling food into their reach, and afterwards they could reciprocate favours in another task, i.e. pushing down a lever (Schweinfurth \& Taborsky, 2017). Rats donated more food to cooperative partners even if using a different task than their partner. Hence, mere copying is unlikely to explain reciprocity in rats.

Finally, all the above-cited experimental devices used to test reciprocal cooperation in rats required a pre-training phase to familiarise rats with the task. Whereas training is indispensable to ensure task comprehension, overtraining might influence results in unexpected ways (cf. Marshall-Pescini, Dale, Quervel-Chaumette, \& Range, 2016). To rule out this possibility rats were tested in a paradigm involving a natural behaviour, for which no training was needed (Schweinfurth, Stieger \& Taborsky, 2017). Here, focal rats experienced cooperative high-rate groomers, which could lick off saltwater from their neck, and uncooperative low-rate groomers, which were separated from focal rats when saltwater was applied. In a subsequent test phase, focal rats groomed cooperative groomers more often than uncooperative ones. This experimental design shows that natural behaviours are also reciprocated and thus rules out that reciprocal cooperation in rats is a mere product of conditioning. Taken together, these experiments underline the finding that rats help each other conditional on the partner's previous cooperating level, which are unlikely to be explained by task-derived alternative explanations. 


\section{Information used in the process of donating food}

While these studies demonstrate that rats exchange help reciprocally, they tell us little about how rats experience their partner's help and decide upon later returns. A first step for understanding how rats make their decisions is to investigate their perception of others. To understand rats' social experience, it is important to consider their sensory systems, which differ greatly from ours.

Rats are mainly active during dusk and dawn (Telle, 1966). Accordingly, their visual system is poorly developed compared to other diurnal mammals and visual communication plays a minor role during their social interactions (Prusky, Harker, Douglas \& Whishaw, 2002). Therefore, it may not come as a surprise that rats reciprocated food, even if their partner was not visible (Dolivo \& Taborsky, 2015a). In contrast, if they could see but not smell their partner, rats stopped donating food reciprocally (Gerber, Schweinfurth, \& Taborsky, 2020). Furthermore, if the smell of a cooperating individual was blown into the compartment of a focal rat, the latter was more likely to provide food to a stooge than if the smell of a defecting individual was blown in (Gerber et al., 2020). This reveals that other senses than vision are of major importance when detecting helpful behaviours.

Taste also plays a role. Rats directly compete with humans over resources almost all over the world, which is why they have been subject to poisoning for decades (Meerburg, Singleton, \& Leirs, 2009). As a response, rats commonly taste small amounts of new food to assess its harmfulness, emphasising their fine sense of taste (Berdoy \& Smith, 1993). Their finely developed taste sense is probably involved in helping decisions by assessing the quality of received help. Rats find bananas preferable over carrots and hence rats that had received as many banana pieces from one partner as carrot pieces from another, showed a higher propensity to deliver oat flakes to the first partner despite the amount of help was the same (Dolivo \& Taborsky, 2015b). This highlights that rats value different qualities of help independent of the quantity of donations.

Rats communicate with each other by different ultrasonic calls (Brudzynski, 2009). One particular call, the $50 \mathrm{kHz}$ call, has been shown to influence decisions to help. Potential recipients vocalise in this 
ultrasonic range. Their partners respond to the calls and provide help based on the amount of such vocalisations (Łopuch \& Popik, 2011; Schweinfurth \& Taborsky, 2018a).

In addition to communication that involves only a single modality, rats are likely to communicate and perceive cues and signals with all available senses. Partner rats communicate their need for assistance more intensively when in greater need, i.e. being hungry, to which rats respond appropriately (Márquez et al., 2015; Schweinfurth \& Taborsky, 2018a). This interplay involves multiple sensory modalities like visual (Márquez et al., 2015; Schweinfurth \& Taborsky, 2018a), acoustic (Łopuch \& Popik, 2011; Schweinfurth \& Taborsky, 2018a) and olfactory cues by the partners (Schneeberger \& Taborsky, 2020). Whether the information of different modalities is redundant, additive or modulating is currently unknown (cf. Partan \& Marler, 2005).

These studies illustrate that rats experience cooperative situations in several sensory modalities, of which vision is probably of minor importance. In fact, their decisions to help are fine-tuned on information such as the value of help and the partner's need to receive help. Future studies are needed to assess which other information may be integrated in decisions to help.

\section{Different commodities of help}

Almost all experimental studies on reciprocal cooperation in any species have focussed on the manipulation of one commodity, i.e. food donations (but see: Hemelrijk, 1994). However, there is no reason to assume that reciprocity is limited to food. Indeed, there exists plenty of evidence (mostly correlational) for reciprocal allogrooming/allopreening, predator defence, predator inspection and vigilance in a range of species (reviewed in: Taborsky et al., 2016). Rats reciprocally exchange another commodity than food, as well. Rats groom partners that previously groomed them more often than uncooper- 
ative ones (Schweinfurth, et al., 2017). Such reciprocal allogrooming has important fitness consequences. Rats that had groomed their cage mates reciprocally during repeated mild stressors throughout their life, lived longer and suffered less mammary tumours by the end of it (Yee et al., 2008).

These results underline the relevance of reciprocal help in rats within a given commodity. Still, it remains elusive whether rats are equally likely to reciprocally exchange different commodities. Reciprocations between different commodities have been considered to be especially cognitively challenging because different commodities may interact and have different currencies that influence calculations of fair trades (Noë \& Hammerstein, 1995; Stevens \& Gilby, 2004). One study found that rats engaged in reciprocal cooperation involving two different commodities, namely allogrooming and food provisioning (Schweinfurth \& Taborsky, 2018b). Focal rats experienced a partner either cooperating or noncooperating in one of the two commodities. Afterwards, the rats had the opportunity to reciprocate favours by the alternative commodity, i.e. allogrooming the partner after having received food from it, or donating food after having been allogroomed. The focal rats groomed more often cooperative than uncooperative food providers and they donated food more often to partners that had cooperatively groomed them before. This shows that rats engage in reciprocal cooperation involving different commodities, which might be achieved by less demanding cognitive processes than calculating currencies.

\section{Memorising cooperation levels of social partners}

In order to help reciprocally, individuals need to memorise help associated with a specific partner. Memorising social partners and their cooperation level can become challenging, especially if such information exists for multiple partners and needs to be stored over long time intervals (reviewed in: Crystal, 2018). Based on this assumption, reciprocity has been assumed to be cognitively too demanding for most non-human animals (e.g. Stevens et al., 2005). However, a study testing for long-term memory of reciprocal acts demonstrated that rats remembered cooperative partners for at least 
seven days - an information that they incorporated in their cooperative decisions (Stieger, Schweinfurth, \& Taborsky, 2017). During this time, they had constant interactions with social partners in their home cages. This suggests that a time delay of at least seven days and accompanying interfering social events with other partners did not limit reciprocal cooperation in rats. While they can recollect their partner' cooperation levels over this surprisingly long time span, it is still unclear which exact information they remember. Because partners are rarely either cooperators or defectors, there are several ways for how to memorise social partners. Social information gathered during multiple encounters with the same individual might be conflicting, i.e. a partner might have cooperated most of the times, but also defected every now and then (cf. Stevens et al., 2005). Remembering such accumulating amounts of information of different partners might further increase the cognitive load. However, other mechanisms might reduce the need of storing such amounts of information.

One way to reduce memory effort is the formation of social bonds. Social bonds or friendships are characterised by close, enduring and cooperative relationships between conspecifics (Silk, 2003). By such repeated interactions with a subset of group members, fewer individuals need to be remembered and cooperation may be based on the bonding state rather than on remembering single cooperative acts or involved calculations on received and already reciprocated favours. This mechanisms has been proposed to be the basis for most primate reciprocations, including humans (Schino \& Aureli, 2009). Interestingly, rats do not form stable social bonds (Schweinfurth, Neuenschwander, et al., 2017), making such simple mechanism improbable in their cooperative interactions.

Instead of accumulating information on partners over long time spans, rats may lower the cognitive load by remembering the most recent social event with particular partners, which may be updated after every new interaction. Indeed, rats who had repeatedly experienced social partners over several food provisioning events considered only the last experiences when deciding to donate food to them (Schweinfurth \& Taborsky, 2019). Importantly, the result could not be explained by limited memory capacity because they remembered former interactions beyond last encounters (Schweinfurth \& 
Taborsky, 2019). This result may explain the lack of enduring social bonds because apparently social information is not accumulated. Considering last encounters reduces memory effort, which enables them to memorise social information over several days.

\section{Cognitive mechanisms underlying reciprocity in rats}

Decision rules, such as 'I help you because you helped me' may appear highly cognitively demanding. To understand the cognitive requirements enabling individuals to follow such rules, different cognitive mechanisms of reciprocity, i.e. symmetry-based, calculated, emotional and attitudinal reciprocity have been proposed (Brosnan \& de Waal, 2002; Schino, di Giuseppe, \& Visalberghi, 2009).

Symmetry-based reciprocity leads to reciprocal patterns due to shared symmetrical traits such as relatedness or rank similarities of a pair. In this reciprocity type, provided help is not based on received help, rather it is a product of, for instance, shared time due to equal dominance ranks. Most experimental studies in rats have therefore used the same partner in two situations, i.e. cooperating and defecting, thereby trying to disentangle symmetrical traits from experienced cooperation (e.g., Li \& Wood, 2017; Schweinfurth, Stieger, et al., 2017; Schweinfurth \& Taborsky, 2018b, 2019; Stieger et al., 2017; Viana et al., 2010). As rats donated more food to the same individual, when it was cooperative than when it withdrew from helping in another situation, any symmetrical factors can be excluded as they did not differ between the situations.

Under the hypothesis of calculated reciprocity, individuals are expected to calculate and memorise received and given favours. Such calculations are mainly constrained by temporal discounting, different service values and numerical discrimination (Stevens \& Hauser, 2004). First, temporal discounting, i.e. the devaluation of future rewards (Weibull, 1985), can potentially influence reciprocal cooperation (e.g. Stephens, McLinn, \& Stevens, 2002). It is assumed that by devaluing future rewards, individuals would always opt for secure immediate rewards rather than investing into reciprocal interactions and 
uncertain delayed benefits. In fact, Norway rats show high temporal discounting by completely devaluing future rewards within 30 seconds (Richards, Mitchell, de Wit, \& Seiden, 1997). Second, such calculations between received and given favours might be even more demanding, if favours differ in qualities. Finally, limited abilities of numerical discrimination can result in inappropriate returns, which eventually makes reciprocal cooperation unlikely. Rats have been shown to count within the range of six entities (Davis \& Bradford, 1986) and discriminate between quantities only if the differences are large (Cox \& Tamara Montrose, 2016). Although rats show all these constraints to calculate reciprocal decisions, they reciprocate help. First, despite being constrained by high temporal discounting, rats have been shown to reciprocate help even with a delay of at least seven days (Stieger et al., 2017). This time discrepancy illustrates that temporal discounting is unlikely to influence reciprocal cooperation in rats. Second, rats are able to exchange allogrooming with food (Schweinfurth \& Taborsky, 2018b). Thus, different currencies with different values appear not to restrict such exchanges, too. Finally, studies find reciprocal cooperation in rats even if the received amount of help is above the countable range, i.e. above six items (e.g. Schweinfurth et al., 2017). Taken together, these examples show that calculating received and given help is unlikely in rats.

Emotional bookkeeping describes that reciprocity can be achieved by helping only those with which individuals associate positive emotions that are based on long-term social bonds. This emotionalbased reciprocity is unlikely to explain reciprocity in rats because rats apparently do not form such social bonds (Schweinfurth et al., 2017). A mechanism similar to emotional bookkeeping is attitudinal reciprocity. Here, decisions are not based on long-lasting emotions associated with social partners but rather on short-term positive experiences, i.e. attitudes. Indeed, rats reciprocate favours according to last encounters (Schweinfurth \& Taborsky, 2019).

Given the above-summarised evidence, it seems unlikely that rats base their decisions on similarities, cost-benefit calculations or on long-term emotional bonds. It seems more likely that they use the computationally less demanding form of attitudinal reciprocity. Here, attitudes are formed based on 
single encounters that are over-written by the subsequent meeting with the same partner. Such attitudes may be additionally modulated by the quality of received help (Dolivo \& Taborsky, 2015b).

\section{Summary}

Reciprocity is a frequently debated explanation of cooperation between non-human animals. Norway rats are amongst the best-understood model systems in reciprocal cooperation. Wild-derived and domesticated individuals cooperate reciprocally with each other, independent of sex or kinship. They exchange help within and between different commodities, value the quality of help and memorise social partners over long time intervals. Thereby their cooperative effort is fine-tuned on their partner's communication of need. They possibly achieve all this by forming an attitude towards their social partner based on the last encounter. Importantly, these studies are based on the manipulation of the cooperation experience, allowing causal conclusions about the decisions to help. The studies show that reciprocal cooperation is not restricted to humans or other large-brained animals. Careful studies in both the lab and field for a range of species are needed to draw firm conclusion about how widespread reciprocal cooperation really is in other non-human animals.

\section{Acknowledgements}

I would like to thank Allison Kaufmann, Joachim Frommen and Josep Call for helpful discussions and comments. Further, I am grateful to Valentina Balzarini for drawings. The Swiss National Science Foundation provided funding (P2BEP3_175269). 


\section{Literature}

Alexander, R. D. (1987). The biology of moral systems. New York: AldineTransaction.

Amici, F., Aureli, F., Mundry, R., Amaro, A. S., Barroso, A. M., Ferretti, J., \& Call, J. (2014). Calculated reciprocity? A comparative test with six primate species. Primates, 55(3), 447-457.

Axelrod, R., \& Hamilton, W. D. (1981). The evolution of cooperation. Science, 211, 1390-1396.

Barnett, S. A. (1963). The rat - a study in behavior. New Jersey: AldineTransaction, A division of Transaction Publishers, Rutgers - The State University.

Barnett, S. A., \& Spencer, M. M. (1951). Feeding, social behaviour and interspecific competition in wild rats. Behaviour, 3(3), 229-242.

Ben-Ami Bartal, I., Decety, J., \& Mason, P. (2011). Empathy and pro-social behavior in rats. Science, $334,1427-1430$.

Ben-Ami Bartal, I., Rodgers, D. A., Bernardez Sarria, M. S., Decety, J., \& Mason, P. (2014). Pro-social behavior in rats is modulated by social experience. eLife, e01385-01385.

Ben-Ami Bartal, I., Shan, H., Molasky, N. M. R., Murray, T. M., Williams, J. Z., Decety, J., \& Mason, P. (2016). Anxiolytic treatment impairs helping behavior in rats. Frontiers in Psychology, 7, 850.

Berdoy, M., \& Smith, P. (1993). Arms race and rat race: adaptations against poisoning in the brown rat. Ecological Reviews, 48, 215-228.

Bowles, S., \& Gintis, H. (2011). A cooperative species - human reciprocity and its evolution. Princeton: Princeton University Press.

Boyd, R., \& Richerson, P. J. (1989). The evolution of indirect reciprocity. Social Networks, 11, 213-236.

Brenes, J. C., \& Fornaguera, J. (2008). Effects of environmental enrichment and social isolation on sucrose consumption and preference: associations with depressive-like behavior and ventral striatum dopamine. Neuroscience Letters, 436, 278-282.

Brosnan, S. F., \& de Waal, F. B. M. (2002). A proximate perspective on reciprocal altruism. Human Nature, 13(1), 129-152.

Brudzynski, S. M. (2009). Communication of adult rats by ultrasonic vocalization: biological, sociobiological, and neuroscience approaches. The Neurobiology of Social Behavior, 50(1), 4350.

Burkart, J. M., \& van Schaik, C. P. (2013). Group service in macaques (Macaca fuscata), capuchins (Cebus apella) and marmosets (Callithrix jacchus): a comparative approach to identifying proactive prosocial motivations. Journal of Comparative Psychology, 127(2), 212-225.

Carter, G. G. (2014). The reciprocity controversy. Animal Behavior and Cognition, 1(3), 368-386.

Clements, K. C., \& Stephens, D. W. (1995). Testing models of non-kin cooperation: mutualism and the Prisoner's dilemma. Animal Behaviour, 50(2), 527-535.

Clutton-Brock, T. (2009). Cooperation between non-kin in animal societies. Nature, 462(7269), 51-57.

Colin, C., \& Desor, D. (1986). Differenciations comportementales dans des groupes de rats soumis a une difficulte d'acces de la nourriture. Behavioral Processes, 13, 85-100.

Cox, L., \& Tamara Montrose, V. (2016). Quantity discrimination in domestic rats, Rattus norvegicus. Animals, 6, 46. 
Cronin, K. A., Schroeder, K. K. E., \& Snowdon, C. T. (2010). Prosocial behaviour emerges independent of reciprocity in cottontop tamarins. Proceedings of the Royal Society B: Biological Sciences, 277(1701), 3845-3851.

Crystal, J. D. (2018). Comparative cognition: rats pay back quid pro quo. Current Biology, 28(4), 153155.

Darwin, C. (1859). On the origins of species. London: John Murray.

Davis, H., \& Bradford, S. A. (1986). Counting behavior by rats in a simulated natural environment. Ethology, 73(4), 265-280.

de Waal, F. B. M., \& Berger, M. L. (2000). Payment for labour in monkeys. Nature, 404, 563.

Dolivo, V., Rutte, C., \& Taborsky, M. (2016). Ultimate and proximate mechanisms of reciprocal altruism in rats. Learning \& Behavior, 44, 223.

Dolivo, V., \& Taborsky, M. (2015a). Cooperation among Norway rats: the importance of visual cues for reciprocal cooperation, and the role of coercion. Ethology, 121, 1071-1080.

Dolivo, V., \& Taborsky, M. (2015b). Norway rats reciprocate help according to the quality of help they received. Biology Letters, 11, 20140959.

Dugatkin, L. A. (1997). Cooperation among animals - an evolutionary perspective. Oxford: Oxford University Press.

Gerber, N., Schweinfurth, M. K., \& Taborsky, M. (2020). The smell of cooperation: rats reciprocate help based on odour cues of helpful conspecifics. Proceedings of the Royal Society B 287: 20202327.

Gheusi, G., Goodall, G., \& Dantzer, R. (1997). Individually distinctive odours represent individual conspecifics in rats. Animal Behaviour, 53(5), 935-944.

Grasmuck, V., \& Desor, D. (2002). Behavioural differentiation of rats confronted to a complex divingfor-food situation. Behavioural Processes, 58(1-2), 67-77.

Hamilton, W. D. (1964). The genetical evolution of social behaviour. I. Journal of Theoretical Biology, 7(1), 1-16.

Hammerstein, P. (2003). Why is reciprocity so rare in social animals? In P. Hammerstein (Ed.), Genetic and cultural evolution of cooperation (pp. 83-93). Cambridge: MIT Press.

Hemelrijk, C. K. (1994). Support for being groomed in long-tailed macaques, Macaca fascicularis. Animal Behaviour, 48, 479-481.

Hernandez-Lallement, J., van Wingerden, M., Marx, C., Srejic, M., \& Kalenscher, T. (2015). Rats prefer mutual rewards in a prosocial choice task. Frontiers in Neuroscience, 8, 443.

Hopp, S. L., Owren, M. J., \& Marion, J. R. (1985). Olfactory discrimination of individual littermates in rats (Rattus norvegicus). Journal of Comparative Psychology, 99(2), 248-251.

Horn, L., Scheer, C., Bugnyar, T., \& Massen, J. J. M. (2016). Proactive prosociality in a cooperatively breeding corvid, the azure-winged magpie (Cyanopica cyana). Biology Letters, 12(10), 20160649.

House, B., Henrich, J., Sarnecka, B., \& Silk, J. B. (2013). The development of contingent reciprocity in children. Evolution and Human Behavior, 34(2), 86-93.

Hurst, J., Barnard, C. J., Nevison, C. M., \& West, C. D. (1997). Housing and welfare in laboratory rats: welfare implications of isolation and social contact among caged males. Animal Welfare, 6, 329347. 
Krafft, B., Colin, C., \& Peignot, P. (1994). Diving-for-food: a new model to assess social roles in a group of laboratory rats. Ethology, 96, 11-23.

Krause, J., \& Ruxton, G. D. (2002). Living in groups. Oxford Series in Ecology and Evolution.

Li, G. R., \& Wood, R. I. (2017). Male rats play a repeated donation game. Physiology and Behavior, 174, 95-103.

Littman, R. A., Lanski, L. M., \& Rhine, R. J. (1954). Studies of individual and paired interactional problem solving behavior of rats (Mus norvegicus albinus). Behaviour, 7(2/3), 189-206.

Łopuch, S., \& Popik, P. (2011). Cooperative behavior of laboratory rats (Rattus norvegicus) in an instrumental task. Behaviour, 125(2), 250-253.

MacDonald, D. W., Mathews, F., \& Berdoy, M. (1999). The behaviour and ecology of Rattus norvegicus: from opportunism to kamikaze tendencies. In Grant R. Singleton, Lyn A. Hinds (Ed.), Ecologicallybased management of rodent pests (pp. 49-80). Canberra.

Márquez, C., Rennie, S. M., Costa, D. F., \& Moita, M. M. (2015). Prosocial choice in rats depends on food-seeking behavior displayed by recipients. Current Biology, 25(13), 1736-1745.

Marshall-Pescini, S., Dale, R., Quervel-Chaumette, M., \& Range, F. (2016). Critical issues in experimental studies of prosociality in non-human species. Animal Cognition, 19(4), 679-705.

Massen, J. J. M., van den Berg, L. M., Spruijt, B. M., \& Sterck, E. H. M. (2010). Generous leaders and selfish underdogs: pro-sociality in despotic macaques. PLoS One, 5(3), 1-5.

Meerburg, B. G., Singleton, G. R., \& Leirs, H. (2009). The year of the rat ends - time to fight hunger! Pest Management Science, 65(4), 351-352.

Munn, N. L. (1950). Handbook of psychological research on the rat. Massachusetts U.S.A.: The Riverside Press Cambridge.

Noë, R., \& Hammerstein, P. (1995). Biological markets. Trends in Ecology and Evolution, 10(8), 336339.

Partan, S. R., \& Marler, P. (2005). Issues in the classification of multimodal communication signals. The American Naturalist, 166(2), 231-245.

Prusky, G. T., Harker, K. T., Douglas, R. M., \& Whishaw, I. Q. (2002). Variation in visual acuity within pigmented, and between pigmented and albino rat strains. Behavioural Brain Research, 136, 339-348.

Puckett, E. E., Park, J., Combs, M., Blum, M. J., Bryant, J. E., Caccone, A., ... Munshi-South, J. (2016). Global population divergence and admixture of the brown rat (Rattus norvegicus). Proceedings of the Royal Society B: Biological Sciences, 283(1841), 20161762.

Quervel-Chaumette, M., Dale, R., Marshall-Pescini, S., \& Range, F. (2015). Familiarity affects otherregarding preferences in pet dogs. Scientific Reports, 5, 18102.

Ramseyer, A., Pelé, M., Dufour, V., Chauvin, C., \& Thierry, B. (2006). Accepting loss: the temporal limits of reciprocity in brown capuchin monkeys. Proceedings of the Royal Society B: Biological Sciences, 273(1583), 179-184.

Richards, J. B., Mitchell, S. H., de Wit, H., \& Seiden, L. S. (1997). Determination of discount functions in rats with an adjusting-amount procedure. Journal of the Experimental Analysis of Behaviour, 67(3), 353-366.

Rutte, C., \& Taborsky, M. (2007). Generalized reciprocity in rats. PLoS Biology, 5(7), 1421-1425. 
Rutte, C., \& Taborsky, M. (2008). The influence of social experience on cooperative behaviour of rats (Rattus norvegicus): direct vs generalised reciprocity. Behavioral Ecology and Sociobiology, 62(4), 499-505.

Sato, N., Tan, L., Tate, K., \& Okada, M. (2015). Rats demonstrate helping behavior toward a soaked conspecific. Animal Cognition, 18, 1039-1047.

Schino, G., \& Aureli, F. (2009). Reciprocal altruism in primates: partner choice, cognition, and emotions. Advances in the Study of Behavior, 39, 45-69.

Schino, G., \& Aureli, F. (2010). Primate reciprocity and its cognitive requirements. Evolutionary Anthropology, 19(4), 130-135.

Schino, G., di Giuseppe, F., \& Visalberghi, E. (2009). The time frame of partner choice in the grooming reciprocation of Cebus apella. Ethology, 115(1), 70-76.

Schmid, R., Schneeberger, K., \& Taborsky, M. (2017). Feel good - do good? Disentangling reciprocity from unconditional prosociality. Ethology, 123, 640-6470.

Schneeberger, K., Dietz, M., \& Taborsky, M. (2012). Reciprocal cooperation between unrelated rats depends on cost to donor and benefit to recipient. BMC Evolutionary Biology, 12(1), 41.

Schneeberger, K., Röder, G., \& Taborsky, M. (2020). The smell of hunger: Norway rats provision social partners based on odour cues of need. PLoS Biology 18 (3), e3000628.

Schuster, R. H., \& Perelberg, A. (2004). Why cooperate? An economic perspective is not enough. Behavioural Processes, 66, 261-277.

Schwab, C., Swoboda, R., Kotrschal, K., \& Bugnyar, T. (2012). Recipients affect prosocial and altruistic choices in jackdaws, Corvus monedula. PloS One, 7(4), e34922.

Schwartz, L. P., Silberberg, A., Casey, A. H., Kearns, D. N., \& Slotnick, B. (2016). Does a rat release a soaked conspecific due to empathy? Animal Cognition, 20, 299-308.

Schweinfurth, M. K., Aeschbacher, J., Santi, M., \& Taborsky, M. (2019). Male Norway rats cooperate according to direct but not generalized reciprocity rules. Animal Behaviour, 152, 93-101.

Schweinfurth, M. K., \& Call, J. (2019a). Reciprocity: different behavioural strategies, cognitive mechanisms and psychological processes. Learning and Behavior, 47, 284-301.

Schweinfurth, M. K., \& Call, J. (2019b). Revisiting the possibility of reciprocal help in non-human primates. Neuroscience \& Biobehavioral Reviews, 104, 73-86.

Schweinfurth, M. K., Neuenschwander, J., Engqvist, L., Schneeberger, K., Rentsch, A. K., Gygax, M., \& Taborsky, M. (2017). Do female Norway rats form social bonds? Behavioral Ecology and Sociobiology, 71(6), 98.

Schweinfurth, M. K., Stieger, B., \& Taborsky, M. (2017). Experimental evidence for reciprocity in allogrooming among wild-type Norway rats. Scientific Reports, 7(1), 4010.

Schweinfurth, M. K., \& Taborsky, M. (2016). No evidence for audience effects in reciprocal cooperation of Norway rats. Ethology, 122(6), 513-521.

Schweinfurth, M. K., \& Taborsky, M. (2017). The transfer of alternative tasks in reciprocal cooperation. Animal Behaviour, 131, 35-41.

Schweinfurth, M. K., \& Taborsky, M. (2018a). Norway rats (Rattus norvegicus) communicate need, which elicits donation of food. Journal of Comparative Psychology, 132(2), 119-129. 
Schweinfurth, M. K., \& Taborsky, M. (2018b). Reciprocal trading of different commodities in Norway rats. Current Biology, 28, 594-599.

Schweinfurth, M. K., \& Taborsky, M. (2018c). Relatedness decreases and reciprocity increases cooperation in Norway rats. Proceedings of the Royal Society B: Biological Sciences, 285, 20180035.

Schweinfurth, M. K., \& Taborsky, M. (2019). Rats play tit-for-tat instead of integrating social experience over multiple interactions. Proceedings of the Royal Society B: Biological Sciences, 286, 20192423.

Silberberg, A., Allouch, C., Sandfort, S., Kearns, D. N., Karpel, H., \& Slotnick, B. (2013). Desire for social contact, not empathy, may explain "rescue" behavior in rats. Animal Cognition, 17, 609-618.

Silk, J. B. (2003). Cooperation without counting - the puzzle of friendship. In P. Hammerstein (Ed.), Genetic and cultural evolution of cooperation (pp. 37-54). Cambridge: MIT Press.

Silk, J. B. (2007). The strategic dynamics of cooperation in primate groups. Advances in the Study of Behavior, 37, 1-41.

Simones, P. M. V. (2007). Cooperation in rats playing an iterated Prisoner's dilemma game: influence of a game matrix formed with qualitatively distinct payoffs. MSc thesis, University of Lisbon, Lisbon.

Stephens, D. W., McLinn, C. M., \& Stevens, J. R. (2002). Discounting and reciprocity in an iterated Prisoner's dilemma. Science, 298(5601), 2216-2218.

Stevens, J. R., Cushman, F. A., \& Hauser, M. D. (2005). Evolving the psychological mechanisms for cooperation. Annual Review of Ecology, Evolution, and Systematics, 36(1), 499-518.

Stevens, J. R., \& Gilby, I. C. (2004). A conceptual framework for nonkin food sharing: timing and currency of benefits. Animal Behaviour, 67(4), 603-614.

Stevens, J. R., \& Hauser, M. D. (2004). Why be nice? Psychological constraints on the evolution of cooperation. Trends in Cognitive Sciences, 8(2), 60-65.

Stieger, B., Schweinfurth, M. K., \& Taborsky, M. (2017). Reciprocal allogrooming among unrelated Norway rats (Rattus norvegicus) is affected by previously received cooperative, affiliative and aggressive behaviours. Behavioral Ecology and Sociobiology, 71, 182.

Suchak, M., Eppley, T. M., Campbell, M. W., Feldman, R. A., Quarles, L. F., \& de Waal, F. B. M. (2016). How chimpanzees cooperate in a competitive world. Proceedings of the National Academy of Sciences of the United States of America, 113(36), 10215-10220.

Taborsky, M., Frommen, J. G., \& Riehl, C. (2016). Correlated pay-offs are key to cooperation. Philosophical Transactions of the Royal Society B: Biological Sciences, 371, 20150084.

Telle, H. (1966). Beitrag zur Erkenntnis der Verhaltensweise von Ratten, vergleichend dargestellt bei Rattus norvegicus und Rattus rattus. Zeitschrift Für Angewandte Zoologie, 53, 129-196.

Trivers, R. L. (1971). The evolution of reciprocal altruism. The Quarterly Review of Biology, 46(1), 3557.

Viana, D. S., Gordo, I., Sucena, E., \& Moita, M. M. (2010). Cognitive and motivational requirements for the emergence of cooperation in a rat social game. PloS One, 5(1), e8483.

Weibull, J. W. (1985). Discounted-value representations of temporal preferences. Mathematics of Operations Research, 10(2), 244-250. 
Wodka, M. B. (2012). Conditions of cooperation between rats in the Prisoner's dilemma model. Honors Projects, 154, http://digitalcommons.iwu.edu/psych_honproj/154.

Wood, R. I., Kim, J. Y., \& Li, G. R. (2016). Cooperation in rats playing the iterated Prisoner's dilemma game. Animal Behaviour, 114, 27-35.

Wrighten, S. A., \& Hall, C. R. (2016). Support for altruistic behavior in rats. Open Journal of Social Sciences, 4, 93-102.

Yee, J. R., Cavigelli, S. A., Delgado, B., \& McClintock, M. K. (2008). Reciprocal affiliation among adolescent rats during a mild group stressor predicts mammary tumors and lifespan. Psychosomatic Medicine, 70(9), 1050-1059.

Zentall, T. R. (2015). Reciprocal altruism in rats: why does it occur? Learning \& Behavior, 44(7), 15-16. 

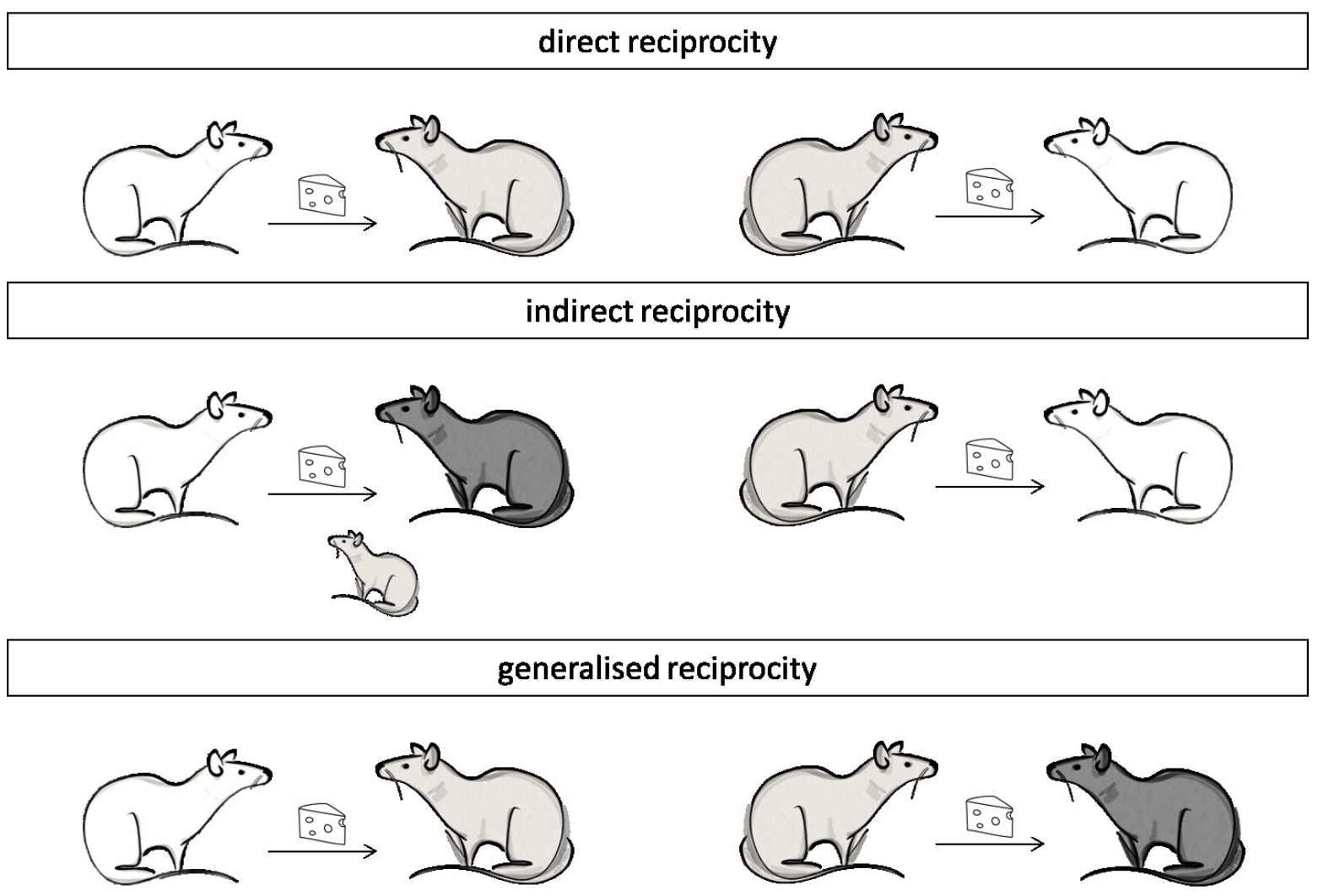

Figure.1. The three different decision rules involved in reciprocal help.

Three reciprocal decision rules have been described, which all lead to evolutionary stable cooperation. In direct reciprocity, individuals help only those that have helped them previously (topmost panel). In contrast, indirect reciprocity relies on public information and individuals help individuals that have been observed to be helpful towards others (middle panel). Finally, generalised reciprocity is based on a general increase of motivation to help based on received help by someone else earlier (lowermost panel). The decision rules are illustrated by rats providing food and thereby being helpful towards each other. Different colours indicate different individuals. In direct reciprocity, the white rat provides food to a grey social partner. After a time delay, this partner pays back the favour to the directly experienced previous donor. In indirect reciprocity, the grey rat observes a white rat providing food to a third individual. Thereafter the grey rat provides food to the previously seen helpful rat. In generalised reciprocity, the grey rat receives help by a social partner. After a while, the grey rat helps an unknown rat. (Drawings kindly provided by Valentina Balzarini.) 


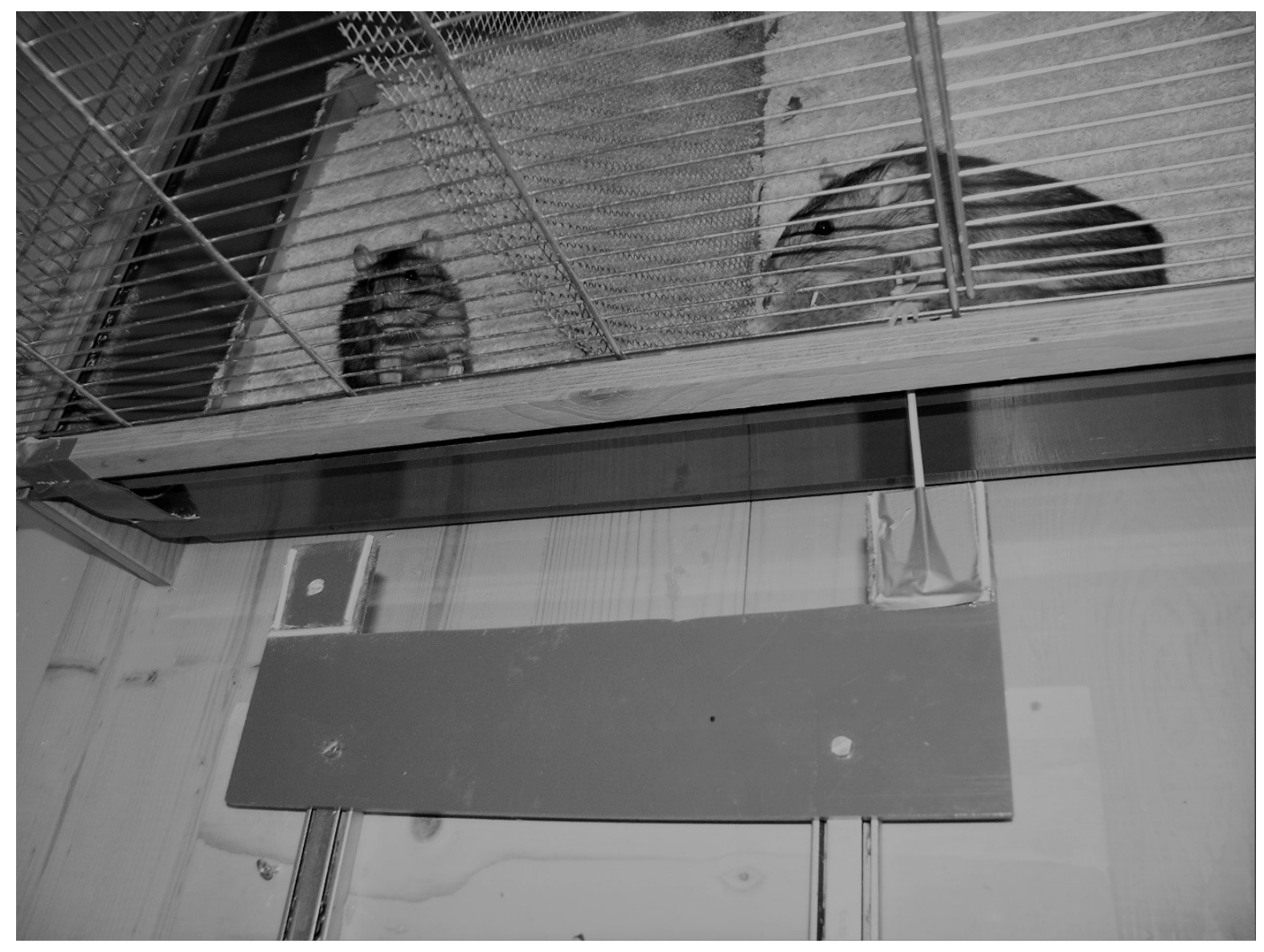

Figure.2. Food-exchange apparatus.

The picture depicts one apparatus of a two-player food exchange task, which has been established by Rutte \& Taborsky, 2007. In front of an experimental cage, which hosts two separated rats, is a movable platform that is connected to a stick. By pulling the stick, the platform moves into the cage and provides food only to the recipient. Afterwards the roles can be exchanged and rats are able to pay back the favour. Other paradigms following the same logic include for instance Skinner boxes (e.g., Wood, Kim, \& Li, 2016) or T-mazes (Márquez et al., 2015). (Picture kindly provided by Michael Taborsky.) 
Table.1

Overview of Studies on Reciprocal Cooperation in Norway Rats

\begin{tabular}{|c|c|c|c|c|c|c|c|}
\hline Study & decision rule & commodity & time delay & prior relationship & sex & strain & task \\
\hline Dolivo \& Taborsky, 2015a & direct & food & 1 day & unfamiliar non-kin & female & wild-type & bar-pull \\
\hline Dolivo \& Taborsky, 2015b & direct & food & 1-2 days & unfamiliar non-kin & female & wild-type & bar-pull \\
\hline \multirow[t]{2}{*}{ Gerber et al., 2020.} & direct \& generalised & food & immediately & unfamiliar non-kin & female & wild-type & bar-pull \\
\hline & & & \& 1 day & & & & \\
\hline Li \& Wood, 2017 & direct & food & immediately & unfamiliar \& familiar & male & Long-Evans & Skinner box \\
\hline Rutte \& Taborsky, 2007 & generalised & food & 1 day & unfamiliar non-kin & female & wild-type & bar-pull \\
\hline Rutte \& Taborsky, 2008 & direct \& generalised & food & 1 day & unfamiliar non-kin & female & wild-type & bar-pull \\
\hline Schmid et al., 2017 & direct & food & 1 day & unfamiliar non-kin & female & wild-type & bar-pull \\
\hline
\end{tabular}




\begin{tabular}{|c|c|c|c|c|c|c|c|}
\hline Schneeberger et al., 2012 & direct \& generalised & food & immediately & unfamiliar non-kin & female & wild-type & bar-pull \\
\hline Schweinfurth et al., 2019 & direct \& generalised & food & 1 day & unfamiliar non-kin & male & wild-type & bar-pull \\
\hline Schweinfurth \& Taborsky, 2019 & direct & food & 1 - 3 day & unfamiliar non-kin & female & wild-type & bar-pull \\
\hline Schweinfurth \& Taborsky, 2016 & direct & food & immediately & unfamiliar non-kin & female & wild-type & bar-pull \\
\hline \multirow[t]{2}{*}{ Schweinfurth et al., 2017} & direct & allogrooming & immediately & familiar non-kin \& fa- & female & wild-type & free interac- \\
\hline & & & & miliar kin & & & tion \\
\hline Schweinfurth \& Taborsky, 2017 & direct & food & immediately & unfamiliar non-kin & female & wild-type & bar-pull \\
\hline Schweinfurth \& Taborsky, 2018 & direct & food & immediately & unfamiliar non-kin & female & wild-type & bar-pull \\
\hline \multirow[t]{2}{*}{ Schweinfurth \& Taborsky, 2018} & direct & food $\leftrightarrow$ allo- & immediately & familiar kin \& non-kin & female & wild-type & bar-pull \& free \\
\hline & & grooming & & & & & interaction \\
\hline Schweinfurth \& Taborsky, 2018 & direct & food & immediately & unfamiliar kin & male & wild-type & bar-pull \\
\hline Simones, 2007 & direct & food & immediately & $?$ & male & Sprague Dawley & T-maze \\
\hline
\end{tabular}




\begin{tabular}{|c|c|c|c|c|c|c|c|}
\hline Stieger et al., 2017 & direct & $\begin{array}{l}\text { food } \rightarrow \text { allo- } \\
\text { grooming }\end{array}$ & 7 days & unfamiliar non-kin & female & wild-type & $\begin{array}{c}\text { bar-pull \& free } \\
\text { interaction }\end{array}$ \\
\hline Viana et al., 2010 & direct & food & immediately & non-litter mates & male & Sprague Dawley & T-maze \\
\hline \multirow[t]{2}{*}{ Wood et al., 2016} & direct & food & immediately & familiar \& unfamiliar & female & Long-Evans & Skinner box \\
\hline & & & & non-kin & \& male & & \\
\hline Yee et al., 2008 & direct & allogrooming & immediately & familiar kin \& non-kin & female & Sprague Dawley & free in \\
\hline
\end{tabular}

tion

This table summarises evidence for reciprocal cooperation in Norway rats. The studies differ vastly in respect to the investigated reciprocal decision rules, i.e. direct or generalised reciprocity, commodity, time frame between given and received favours, relationship of pairs prior the test, sex and strain. In addition, the employed task differed. Rats could either provide food to partner by pulling a bar connected to a platform into the reach of their partner ('bar pull'), press a lever that provided food to a partner ('Skinner box'), choose an arm of a T maze resulting in food donations to their partner ('T maze') or they could freely interact and allogroom partners ('free interaction'). 